\title{
Design of earth-air heat exchanger system
}

Trilok Singh Bisoniya

Correspondence:

tsbisoniya@gmail.com Department of Mechanical

Engineering, Sagar Institute of Research \& Technology-Excellence, Bhopal 462041, India

\section{Springer}

\begin{abstract}
The earth-air heat exchanger (EAHE) is a promising technique which can effectively be used to reduce the heating/cooling load of a building by preheating the air in winter and vice versa in summer. In the last two decades, a lot of research has been done to develop analytical and numerical models for the analysis of EAHE systems. Many researchers have developed sophisticated equations and procedures but they cannot be easily recast into design equations and must be used by trial-and-error. In this paper, the author has developed a one-dimensional model of the EAHE systems using a set of simplified design equations. The method to calculate the earth's undisturbed temperature (EUT) and more recently developed correlations for friction factor and Nusselt number are used to ensure higher accuracy in the calculation of heat transfer. The developed equations enable designers to calculate heat transfer, convective heat transfer coefficient, pressure drop, and length of pipe of the EAHE system. A longer pipe of smaller diameter buried at a greater depth and having lower air flow velocity results in increase in performance of the EAHE system.
\end{abstract}

Keywords: Earth-air heat exchanger; Nusselt number $\left(N_{u}\right)$; Effectiveness of EAHE $(\varepsilon)$; Earth's undisturbed temperature (EUT)

\section{Background}

The consumption of high-grade energy has increased considerably with growing needs to achieve thermal comfort conditions inside buildings, residential, greenhouses, livestock buildings, etc. It is desirable to minimize the use of high-grade energy consumption and to promote the use of renewable energy in order to save the earth from hazardous effects of global warming and ozone layer depletion. Numerous alternative techniques are being currently explored to achieve thermal comfort conditions inside buildings. The earth-air heat exchanger is one of these promising techniques which can effectively be used to preheat the air in winter and vice versa in summer. The temperature of earth at a depth of 1.5 to $2 \mathrm{~m}$ remains fairly constant throughout the year (Bisoniya et al. 2013). This constant temperature is called earth's undisturbed temperature (EUT). The EUT remains higher than ambient air temperature in winter and lower than ambient air temperature in summer. The concept of earth-air heat exchanger (EAHE) is very simple as shown in Fig. 1. The ambient air is drawn through the pipes of the EAHE buried at a particular depth, moderated to EUT, and gets heated in winter and vice versa in summer. In this way, the heating and cooling load of building can be reduced passively.

In the last two decades, a lot of research has been done to develop analytical and numerical models for analysis of the EAHE systems (Mihalakakou et al. 1994; Bojic

(c) 2015 Bisoniya. Open Access This article is distributed under the terms of the Creative Commons Attribution 4.0 International License (http://creativecommons.org/licenses/by/4.0/), which permits unrestricted use, distribution, and reproduction in any medium, provided you give appropriate credit to the original author(s) and the source, provide a link to the Creative Commons license, and indicate if changes were made. 


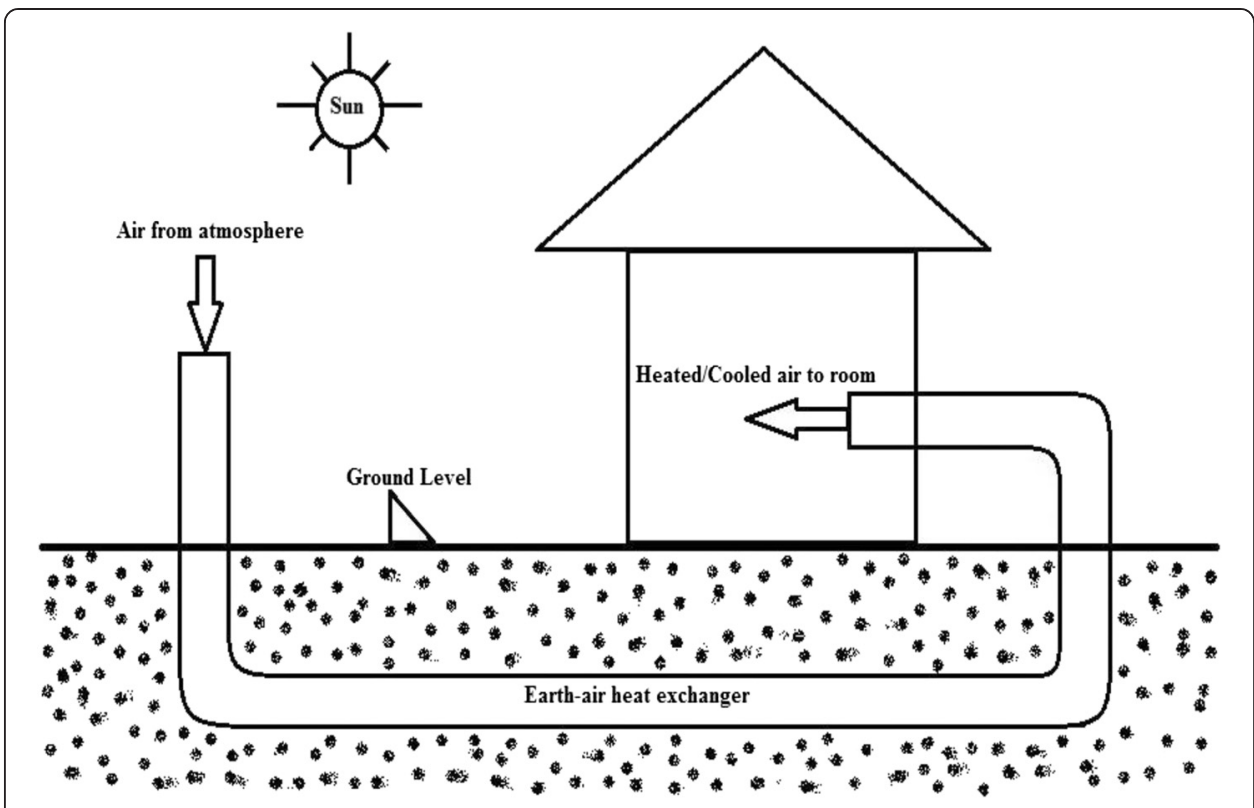

Fig. 1 One-dimensional model of earth-air heat exchanger system

et al. 1997; Gauthier et al. 1997; Hollmuller and Lachal 2001; Su et al. 2012; Sehli et al. 2012; Ozgener et al. 2013). The performance analysis of EAHE involved either the calculation of conductive heat transfer from the pipe to the ground mass or the calculation of convective heat transfer from the circulating air to the pipe and changes in the air temperature and humidity. A number of computer modeling tools are commercially available. EnergyPlus and TRNSYS have EAHE modules that work well; however, these are analysis tools and are not quickly used for design.

Presently, Computational Fluid Dynamics (CFD) is very popular among researchers for modeling and performance analysis of the EAHE systems. The CFD employs a very simple rule of discretization of whole system in small grids. Then, governing equations were applied on these discrete elements to get numerical solutions concerning flow parameters, pressure distribution, and temperature gradients in less time and at reasonable cost because of reduced required experimental work (Kanaris et al. 2006; Wang et al. 2007). For complete analysis of an EAHE system, the use of CFD is recommended, but it is limited to those who have a good command over it. For the initial design of an EAHE system, the use of basic heat transfer equations is more suitable to determine the geometrical dimensions of the system. Many researchers like De Paepe and Janssens (2003), Badescu and Isvoranu (2011), and T'Joen et al. (2012) have developed EAHE design equations and procedures.

In this paper, the author has developed a one-dimensional model of the EAHE system. The method to calculate the EUT and the more recently developed correlations for friction factor and Nusselt number are used to ensure higher accuracy in calculation of heat transfer.

\section{Analysis and modeling of EAHE}

The development of the model of the EAHE system involves the use of basic heat transfer equations. The geometrical dimensions of the EAHE system are decided by 
taking into account the amount of heating or cooling load to be met for space conditioning of the building. The design procedure includes identifying the input parameters which are known to the user and the parameters affecting desired design output. Once the design output is fixed, the heat transfer equations are manipulated to meet the desired output in terms of input parameters.

Therefore, depending on the nature of the design problem the mass flow rate of air, $\dot{m}$; inlet air temperature, $T_{\text {in }}$; desired outlet air temperature from EAHE, $T_{\text {out }}$; and EUT are considered as parameters of the sizing problem. Furthermore, it is considered that the location of installation of the EAHE system is known. So, ambient air temperature and soil properties are known. The EUT temperature is estimated as the annual average ambient air temperature of a particular location; therefore, it is also assumed as a known parameter. The mass flow rate of air and the outlet air temperature are set by the design requirements.

The geometric sizing parameters of an EAHE include the diameter of the pipe, $D$; length of the pipe, $L$; and number of pipes in parallel, $N_{\mathrm{p}}$, in the heat exchanger.

\section{Assumptions}

The following assumptions were made in order to simplify the development of the onedimensional model of the EAHE system:

- The surface temperature of the ground is defined as equal to the ambient air temperature, which equals the inlet air temperature.

- EUT can be approximated to the annual average temperature of the location (Bhopal, India).

- The polyvinyl chloride (PVC) pipe used in the EAHE is of uniform cross-section.

- The thickness of the pipe used in the EAHE is very small; hence, thermal resistance of pipe material is negligible.

- The temperature on the surface of the pipe is uniform in the axial direction.

\section{Boundary conditions}

The following boundary conditions were used in the one-dimensional model of the EAHE system.

\section{Inlet boundary conditions}

At the inlet of the EAHE pipe, the values of air flow velocity, $v_{\mathrm{a}}(\mathrm{m} / \mathrm{s})$, and static temperature of air, $T_{\text {in }}\left({ }^{\circ} \mathrm{C}\right)$, at inlet were to be defined. The thermodynamic properties (density and specific heat capacity) and transport properties (dynamic viscosity and thermal conductivity) of air were to be defined at static temperature of air at inlet.

\section{Outlet boundary conditions}

In a subsonic flow regime, the relative pressure at the outlet of the EAHE pipe was defined as equal to zero atm.

\section{Wall}

The temperature on the surface of pipe (wall) was uniform in axial direction and was defined as equal to earth's undisturbed temperature at Bhopal city $\left(25.2^{\circ} \mathrm{C}\right)$. No slip condition with smooth wall was assumed at the inner surface of the pipe. 


\section{Mass flow rate of air}

The mass flow rate of air is an important parameter, and it must be known by the designer so that the selection of size and number of pipes can be initiated. There is no unique value of size and number of pipes which can meet the EAHE performance. So, the designer has to consider the best combination of the EAHE performance and pumping power required to ensure mass flow rate of air. For a pipe of diameter, $D$; air density, $\rho$; air flow velocity, $v_{\mathrm{a}}$; and number of parallel pipes, $N_{\mathrm{p}}$, the mass flow rate of air through a pipe, $m_{\mathrm{a}}$, is given by:

$$
\dot{m}=\frac{\frac{\pi}{4} D^{2} \rho v_{\mathrm{a}}}{N_{\mathrm{p}}}
$$

For the designer, these parameters have to be determined in such a way that the boundary conditions and the heat exchanger performance are met.

\section{Earth's undisturbed temperature}

The earth's undisturbed temperature is an important parameter in designing an EAHE system. Assuming homogeneous soil of constant thermal diffusivity, the temperature at any depth $z$ and time $t$ can be estimated by the following expression (Labs 1989):

$$
T_{z, t}=T_{m}-A_{\mathrm{s}} \exp \left[-z\left(\frac{\pi}{365 \alpha_{s}}\right)^{\frac{1}{2}}\right] \cos \left\{\frac{2 \pi}{365}\left[t-t_{o}-\frac{z}{2}\left(\frac{365}{\pi \alpha_{s}}\right)^{\frac{1}{2}}\right]\right\}
$$

where $T_{z, t}$ is the ground temperature at time $t(\mathrm{~s})$ and depth $z(\mathrm{~m}), T_{m}$ is the average soil surface temperature $\left({ }^{\circ} \mathrm{C}\right), A_{\mathrm{s}}$ is the amplitude of soil surface variation $\left({ }^{\circ} \mathrm{C}\right), \alpha_{s}$ is the soil thermal diffusivity $\left(\mathrm{m}^{2} / \mathrm{s} ; \mathrm{m}^{2} /\right.$ day $), t$ is the time elapsed from beginning of the calendar year (day), and $t_{o}$ is the phase constant of soil surface (s; days).

It is very difficult to calculate accurately the value of earth's undisturbed temperature because the soil parameters are often unknown. Additionally, it is defined for mean soil properties. Hence, earth's undisturbed temperature is a hypothetical value which can be assumed as equal to the annual average soil surface temperature of a particular locality. The soil surface temperature is assumed equal to the ambient air temperature. So, the earth's undisturbed temperature for Bhopal (Central India) is defined as $25.2{ }^{\circ} \mathrm{C}$ which is equal to the annual average temperature for the same (source: Department of Meteorology, Bhopal).

\section{Methods}

If the dimensions of the EAHE system are known, calculation of the heat transfer rate can be done either by using the log mean temperature difference (LMTD) method or the $\varepsilon$-number of transfer units (NTU) method. In this paper the $\varepsilon$-NTU method is used. The outlet temperature of air was determined by using effectiveness of EAHE $(\varepsilon)$ which is a function of number of transfer units (NTU).

\section{Heat exchanger effectiveness and NTU}

In the earth-air heat exchanger, the medium used for transportation of heat is air only. The heat is released or absorbed by the air flows through the pipe walls by convection and from pipe walls to the surrounding soil and vice versa by conduction. If the contact 
of the pipe wall with the earth is assumed to be perfect and the conductivity of the soil is taken to be very high compared to the surface resistance, then the wall temperature at the inside of the pipe can be assumed to be constant. The expression of NTU depends on different types of flow configurations of the EAHE system. In this paper, the relationship for an evaporator or condenser (with a constant temperature on one side, i.e., wall) was used.

The total heat transferred to the air when flowing through a buried pipe is given by:

$$
Q_{\mathrm{h}}=\dot{m} C_{\mathrm{p}}\left(T_{\text {out }}-T_{\text {in }}\right)
$$

where $\dot{m}$ is the mass flow rate of air $(\mathrm{kg} / \mathrm{s}), C_{\mathrm{p}}$ is the specific heat of air $(\mathrm{J} / \mathrm{kg}-\mathrm{K}), T_{\text {out }}$ is the temperature of air at outlet of EAHE pipe $\left({ }^{\circ} \mathrm{C}\right)$, and $T_{\text {in }}$ is the temperature of air at inlet of EAHE pipe $\left({ }^{\circ} \mathrm{C}\right)$.

Due to convection between the wall and the air, the transferred heat can also be given by:

$$
Q_{\mathrm{h}}=h A \Delta T_{\mathrm{lm}}
$$

where $h$ is the convective heat transfer coefficient $\left(\mathrm{W} / \mathrm{m}^{2}-\mathrm{K}\right)$ and $A$ is the internal surface area of the pipe $\left(\mathrm{m}^{2}\right)$.

The logarithmic average temperature difference $\left(\Delta T_{\mathrm{lm}}\right)$ is given by $\left(T_{\mathrm{EUT}}=T_{\text {wall }}\right)$ :

$$
\Delta T_{\operatorname{lm}}=\frac{T_{\text {in }}-T_{\text {out }}}{\ln \left[\frac{\left(T_{\text {in }}-T_{\text {wall }}\right)}{\left(T_{\text {out }}-T_{\text {wall }}\right)}\right]}
$$

The temperature of air at the outlet of the EAHE pipe can be obtained in an exponential form as a function of the wall temperature and inlet air temperature by eliminating $Q_{\mathrm{h}}$ from Eqs. (3) and (4).

$$
T_{\text {out }}=T_{\text {wall }}+\left(T_{\text {in }}-T_{\text {wall }}\right) e^{-\left(h A / \dot{m} C_{\mathrm{p}}\right)}
$$

If a pipe of infinite length $(A=\infty)$ is used, the air will be heated or cooled to the wall temperature. The effectiveness $(\varepsilon)$ of EAHE for winter heating application can thus be defined as:

$$
\varepsilon=\frac{T_{\text {out }}-T_{\text {in }}}{T_{\text {wall }}-T_{\text {in }}}=1-e^{-\left(h A / \dot{m} C_{\mathrm{p}}\right)}
$$

The non-dimensional group is called the number of transfer units (NTU):

$$
\mathrm{NTU}=\frac{h A}{\dot{m} C_{\mathrm{p}}}
$$

which gives

$$
\varepsilon=1-e^{-\mathrm{NTU}}
$$

The effectiveness of earth-air heat exchanger is determined by the dimensionless group NTU. The variation in earth-air heat exchanger effectiveness as a function of number of transfer units is shown in Fig. 2. It was observed that with increase in value of NTU, the effectiveness also increases but the curve rapidly flattens. The relative gain in effectiveness is very small after the value of NTU becomes more than 3 . There are a 


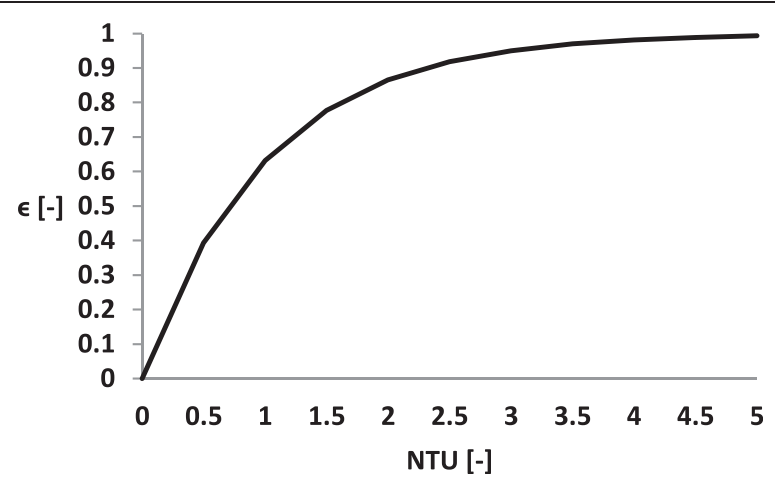

Fig. 2 Earth-air heat exchanger effectiveness as a function of number of transfer units

number of ways to construct an earth-air heat exchanger to obtain a given NTU and thus a desired effectiveness. Similar results were observed by De Paepe and Janssens (2003).

The influence of the design parameters on NTU can be studied in terms of heat transfer and pressure drop. The NTU consists of three parameters, namely, convective heat transfer coefficient $(h)$, internal surface area of pipe $(A)$ and mass flow rate of air $(\dot{m})$ which can vary.

The internal surface area of the pipe is a function of diameter, $D$, and length of EAHE pipe, $L$, both:

$$
A=\pi D L
$$

The convective heat transfer coefficient inside the pipe is defined by:

$$
h=\frac{N_{\mathrm{u}} K}{D}
$$

where $K$ is the thermal conductivity (W/m-K).

Zhang (2009) presented in his $\mathrm{PhD}$ thesis that in conventional earth-to-air heat exchanger (ETAHE) systems, it is typical to have buried ducts with $10 \mathrm{~cm}<\mathrm{D}_{\mathrm{h}}<40 \mathrm{~cm}$ and lengths longer than $20 \mathrm{~m}$. Such sizes mean the ratios of the lengths to the hydraulic diameters $\left(D_{\mathrm{h}}\right)$ are at an order of magnitude of 100 . The hydraulic diameter is defined as four times the ratio of the cross-section area to wetted perimeter of the cross-section.

$$
D_{\mathrm{h}}=\frac{4 A}{P}
$$

where $A$ is the cross-section area and $P$ is the wetted perimeter of the cross-section

The hydraulic diameter for a circular tube is simply the diameter of the tube. Therefore, it is reasonable to assume that the air flows are mostly fully developed in the EAHEs of such sizes and to adapt the corresponding empirical correlations to calculate the convection heat transfer coefficient (CHTC). In order to examine this assumption, eight Nusselt number $\left(N_{\mathrm{u}}\right)$ correlations used by other ETAHE simulation studies (Arzano and Goswami 1997; Bojic et al. 1997, cooling and heating; Singh 1994; De Paepe and Janssens 2003; Hollmuller 2003; Sodha et al. 1994; Benkert and Heidt 1997) were used. Since the correlations were all derived for fully developed turbulent air flow, ideally, they are expected to yield similar values for the same operating condition. The variation of Nusselt number with respect to Reynold's number for a typical design of 
conventional ETAHE was drawn using all eight correlations to calculate the CHTC, and very large differences were observed among the results of the eight correlations. This may be due to different experimental conditions, which were adopted to derive the correlations, for example, the surface roughness of the experimental ducts. The large discrepancies indicate that a suitable correlation has to be selected if one uses any of the existing models to simulate the performance of an EAHE system.

The EAHE system analysed in this paper consists of cylindrical pipes of $0.1016 \mathrm{~m}$ inner diameter made up of PVC with a total burial length of $19.228 \mathrm{~m}$. Assuming that the internal surface of PVC pipes used in the EAHE system is smooth, the $N_{\mathrm{u}}$ correlations given by De and Janssens (2003) can be used to simulate the performance of the system.

$$
N_{\mathrm{u}}=\frac{f / 8\left(R_{\mathrm{e}}-1000\right) P_{\mathrm{r}}}{1+12.7 \sqrt{(f / 8)}\left(P_{\mathrm{r}}^{2 / 3}-1\right)}
$$

(For turbulent flow in tubes with smooth internal surface)

where $R_{\mathrm{e}}$ is the Reynolds number, $P_{\mathrm{r}}$ is Prandtl number, and $f$ is the friction factor for smooth pipes

$$
\text { With } f=\left(1.82 \log R_{\mathrm{e}}-1.64\right)^{-2}
$$

If $2300 \leq R_{\mathrm{e}}<5 \times 10^{6}$ and $0.5<P_{\mathrm{r}}<10^{6}$

The Reynolds number is related to the average air velocity and diameter:

$$
R_{\mathrm{e}}=\frac{\rho v_{\mathrm{a}} D}{\mu}
$$

where $v_{\mathrm{a}}$ is the velocity of air through pipe $(\mathrm{m} / \mathrm{s}), D$ is the diameter of the pipe $(\mathrm{m})$, and $\mu$ is the dynamic viscosity of air $(\mathrm{kg} / \mathrm{m}-\mathrm{s})$.

The Prandtl number is given by:

$$
P_{r}=\frac{\mu c_{\mathrm{p}}}{K}
$$

where $c_{\mathrm{p}}$ is the specific heat of air $(\mathrm{J} / \mathrm{kg}-\mathrm{K})$

\section{Results and discussion}

The thermo-physical properties of materials used in design calculations of EAHE are shown in Table 1 (Bisoniya et al. 2014a; 2014b; 2014c; 2015).

The value of Reynolds number was calculated for air flow velocities of 2, 3.5, and $5 \mathrm{~m} / \mathrm{s}$ and thermo-physical properties of air at $16.7^{\circ} \mathrm{C}$ for winter heating application. The corresponding values of friction factor were calculated by using Eq. (14). The value of Prandtl number for thermo-physical properties of air at $16.7^{\circ} \mathrm{C}$ was calculated as 0.717. After evaluation of Reynolds number, friction factor, and Prandtl number, the

Table 1 Thermo-physical properties of materials used in design calculations of EAHE

\begin{tabular}{lllll}
\hline Material & $\begin{array}{l}\text { Density } \\
\left(\mathrm{kg} / \mathrm{m}^{3}\right)\end{array}$ & $\begin{array}{l}\text { Specific heat capacity } \\
(\mathrm{J} / \mathrm{kg}-\mathrm{K})\end{array}$ & $\begin{array}{l}\text { Thermal conductivity } \\
(\mathrm{W} / \mathrm{m}-\mathrm{K})\end{array}$ & $\begin{array}{l}\text { Dynamic viscosity } \\
(\mathrm{kg} / \mathrm{m}-\mathrm{s})\end{array}$ \\
\hline Air at $16.7^{\circ} \mathrm{C}$ & 1.2185 & 1006 & 0.0253 & $1.804 \mathrm{E}-05$ \\
PVC & 1380 & 900 & 0.16 & - \\
Soil & 2058 & 1843 & 0.54 & - \\
\hline
\end{tabular}


Nusselt number was calculated using Eq. (13) corresponding to air flow velocities of 2, 3.5 , and $5 \mathrm{~m} / \mathrm{s}$.

The variation of Nusselt number with respect to Reynolds number is shown in Fig. 3. It was observed that the value of Nusselt number increases with increase in Reynolds number. Many other researchers (Nakamura and Tamotsu 2004; Luciu et al. 2009) also found that the value of Nusselt number increases with increase in Reynolds number.

The CHTC for different air flow velocities was calculated by using Eq. (11). The CHTC increases with increase in air flow velocity as shown in Fig. 4. Xiao et al. (2011) found that the variation in value of CHTC with a change in air flow velocity has shown similar trends.

The length, $L$, is an independent parameter influencing the NTU. There is a linear variation of NTU with length. Changing either the diameter, $D$, or mass flow rate, $\dot{m}$, changes the air velocity inside the tube. This result in a changing Reynolds number, $R_{\mathrm{e}}$. $D$ and $\dot{m}$ have thus no independent influence on the NTU. In general, lowering $D$ raises the effectiveness; higher flow rates reduce the effectiveness. So, it is better to have several tubes of small diameter over which the flow rate is divided. Long tubes with a small diameter are profitable for the heat transfer. They, however, raise the pressure drop in the tubes, resulting in high fan energy.

\section{Influence on pressure drop}

The pressure drop in a smooth pipe is given by:

$$
\begin{aligned}
& \Delta p=f \frac{L}{D} \rho \frac{v_{\mathrm{a}}^{2}}{2} \\
& f=\frac{64}{R_{\mathrm{e}}} \text { If } R_{\mathrm{e}}<2300 \\
& f=\left(1.82 \log R_{\mathrm{e}}-1.64\right)^{-2} \text { If } R_{\mathrm{e}} \geq 2300
\end{aligned}
$$

It is noted from Eqs. (8) and (17) that both NTU and $\Delta p$ are proportional to the length of the pipe, and the designer can use NTU/L and $\Delta p / L$ as the main performance measures to determine the required length of pipe for design purposes. The length of pipe, $L$, is an independent parameter which has a linear influence on pressure drop. The diameter of the pipe and air flow velocity has a combined effect on pressure drop.

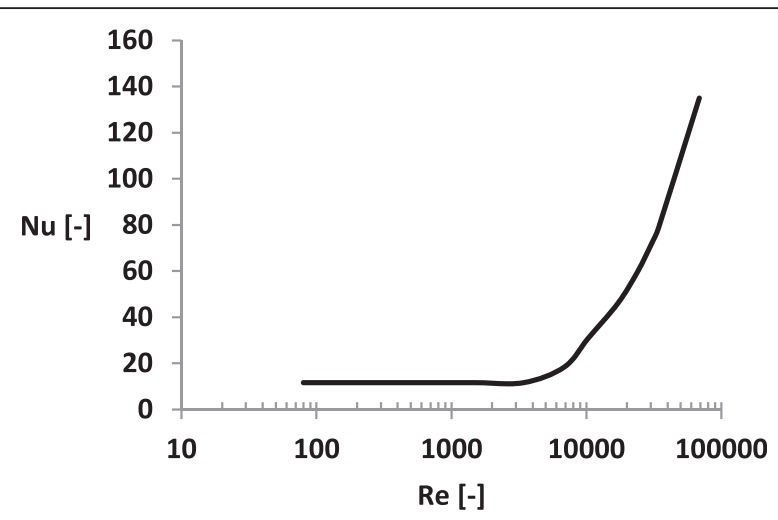

Fig. 3 Variation of Nusselt number with respect to Reynolds number 


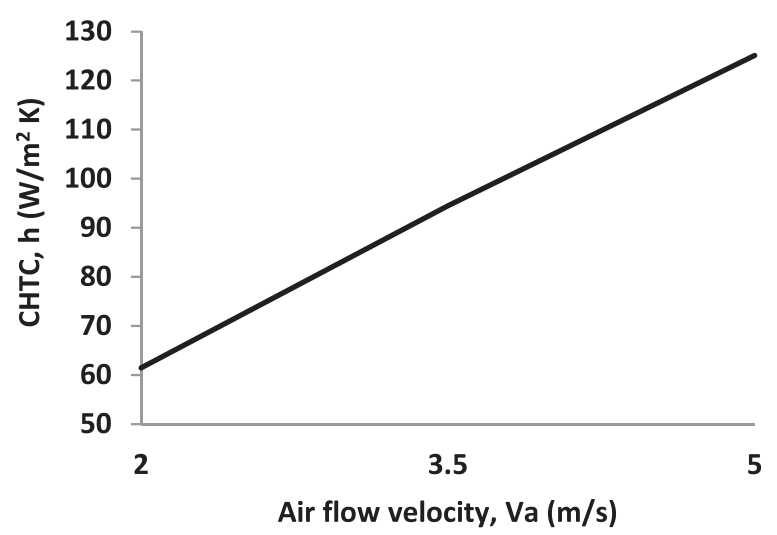

Fig. 4 Convective heat transfer coefficient vs. air flow velocity

The decrease in air flow velocity and increase in diameter of pipe results in decrease in pressure drop. This is in disagreement with the thermal demand of a small diameter. In each case, a large number of pipes are beneficial. The combination of pipe length and diameter has to be optimized.

To evaluate the overall thermo-hydraulic performance of a specific configuration, the Jfactor, introduced by De Paepe and Janssens (2003) was used. It is the ratio of the pressure drop to the NTU value and was shown to be a good performance metric of an earth-air heat exchanger.

$$
J=\frac{\Delta P}{\mathrm{NTU}}
$$

\section{Conclusions}

The earth-air heat exchanger is a promising technique which can effectively be used to preheat the air in winter and vice versa in summer. Many researchers have developed EAHE design equations and procedures. For a complete analysis of the EAHE system, the use of CFD is recommended but it is limited to those who have a good command over it. For the initial design of an EAHE system, the use of basic heat transfer equations is more suitable to determine the geometrical dimensions of the system. In this paper, the author has developed a one-dimensional model of the EAHE system. The method to calculate the EUT and more recently developed correlations for friction factor and Nusselt number are used to ensure higher accuracy in the calculation of heat transfer. The value of EUT for Bhopal (Central India) was calculated as $25.2{ }^{\circ} \mathrm{C}$. It was observed that Nusselt number increases with increase in Reynolds number.

The design of earth-air heat exchanger mainly depends on the heating/cooling load requirement of a building to be conditioned. After calculation of heating/cooling load, the design of the earth-air heat exchanger only depends on the geometrical constraints and cost analysis. The diameter of pipe, pipe length, and number of pipes are the main parameters to be determined. With an increase in length of pipe, both pressure drop and thermal performance increase. A longer pipe of smaller diameter buried at a greater depth and having lower air flow velocity results in an increase in performance of the EAHE system. 


\section{Abbreviations}

CFD: Computational Fluid Dynamics; CHTC: convection heat transfer coefficient; EAHE: earth-air heat exchanger; EUT: earth's undisturbed temperature; LMTD: log mean temperature difference; NTU: number of transfer units; PVC: polyvinyl chloride; TRNSYS: TRaNsient System Simulation software.

\section{Competing interests}

The author declares that he has no competing interests.

Received: 1 June 2015 Accepted: 24 August 2015

Published online: 12 September 2015

\section{References}

Arzano L, Goswami DY (1997) Performance Analysis of a Closed Loop Underground Air Tunnel for Residential Housing in a Hot and Humid Climate. Proceedings of the ISES Solar World Congress, Taejon, South Korea, August 1997

Badescu V, Isvoranu D (2011) Pneumatic and thermal design procedure and analysis of earth-to-air heat exchangers of registry type. Appl Energy 88:1266-1280

Benkert S, Heidt FD, Scholer D (1997) Calculation tool for Earth heat exchangers GAEA. Proceeding of Building Simulation, Fifth International IBPSA Conference, Praque, Czech Republic, pp 9-16, September 1997, 5

Bisoniya TS, Kumar A, Baredar P (2013) Experimental and analytical studies of earth-air heat exchanger (EAHE) systems in India: a review. Renew Sustain Energy Rev 19:238-246

Bisoniya TS, Kumar A, Baredar P (2014a) Cooling potential evaluation of earth-air heat exchanger system for summer season. Int J Eng Tech Res 2(4):309-316

Bisoniya TS, Kumar Anil, Baredar Prashant (2014b) Heating potential evaluation of earth-air heat exchanger system for winter season. Journal of Building Physics, 1-19. doi:10.1177/1744259114542403

Bisoniya TS, Kumar A, Baredar P (2014c) Parametric analysis of Earth-air heat exchanger system based on CFD modelling. Int J Power Renew Energy Syst 1:36-46

Bisoniya TS, Kumar A, Baredar P (2015) Energy metrics of earth-air heat exchanger system for hot and dry climatic conditions of India. Energy Build 86:214-221

Bojic M, Trifunovic N, Papadakis G, Kyritsis S (1997) Numerical simulation, technical and economic evaluation of air-toearth heat exchanger coupled to a building. Energy 22(12):1151-1158

De Paepe M, Janssens A (2003) Thermo-hydraulic design of earth-air heat exchangers. Energy Build 35:389-397

Gauthier C, Lacroix M, Bernier H (1997) Numerical simulation of soil heat exchanger storage system for greenhouse. Sol Energy 60(6):333-346

Hollmuller P (2003) Analytical characterisation of amplitude-dampening and phase-shifting in air/soil heat exchangers. Int J Heat Mass Transf 46:4303-4317

Hollmuller P, Lachal B (2001) Cooling and preheating with buried pipe systems: monitoring, simulation and economic aspects. Energy Build 33(5):509-518

Kanaris AG, Mouza AA, Paras SV (2006) Flow and heat transfer prediction in a corrugated plate heat exchanger using a CFD code. Chem Eng Technol 8:923-930

Labs K (1989) In: Cook J (ed) Passive cooling. Massachusetts, MIT Press, Cambridge

Luciu RS, Mateescu T, Cotorobai V, Mare T (2009) Nusselt number and convection heat transfer coefficient for a coaxial heat exchanger using $\mathrm{Al}_{2} \mathrm{O}_{3}$-water $\mathrm{pH}=5$ nanofluid. Bul Inst Polit lasi 55:71-80

Mihalakakou G, Santamouris M, Asimakopoutos D (1994) Modeling the thermal performance of the earth to air heat exchanger. Sol Energy 53(3):301-305

Nakamura H, Tamotsu I (2004) Variation of Nusselt number with flow regimes behind a circular cylinder for Reynolds numbers from 70 to 30000. Int J Heat Mass Transf 47(23):5169-5173

Ozgener O, Ozgener L, Teste JW (2013) A practical approach to predict soil temperature variations for geothermal (ground) heat exchangers applications. Int J Heat Mass Transf 62:473-480

Sehli A, Hasni A, Tamali M (2012) The potential of earth-air heat exchangers for low energy cooling of buildings in South Algeria. Energy Procedia 18:496-506

Singh SP (1994) Optimization of earth-air tunnel system for space cooling. Energy Convers Manag 35(8):721-725

Sodha MS, Mahajan U, Sawhney RL (1994) Thermal performance of a parallel earth air-pipes system. Int J Energy Res 18(4):437-447

Su H, Liu X-B, Ji L, Mu J-Y (2012) A numerical model of a deeply buried air-earth-tunnel heat exchanger. Energy Build 48:233-239

T'Joen Christophe, Liu Liping, Paepe M De (2012) Comparison of earth-air and earth-water ground tube heat exchangers for residential application. International Refrigeration and Air Conditioning Conference, Paper 1209, http://docs.lib.purdue.edu/iracc/1209

Wang Y, Dong Q, Liu M (2007) Characteristics of fluid flow and heat transfer in shell side of heat exchangers with longitudinal flow of shell side fluid with different supporting structures. International Conference on Power Engineering, Hangzhou, China, 23-27 October 2007

Xiao B, Wang G, Wang Q, Mohammed M, Sisson Jr Richard D, Yiming R (2011) An experimental study of heat transfer during forced air convection. J Mater Eng Perform 20(7):1264-1270

Zhang J (2009) Investigation of airflow and heat transfer in earth-to-air heat exchangers. Ph.D. thesis. Concordia University, Montreal, Quebec, Canada 